respiratory arrhythmia. Am. J. Obstet. Gynecol., 127:662 (1977).

230. Tang, R. C., Chen, I-W., McEnery, P., Brown, D. R., Johnson, R., and Lesnicwicz, J.: Parathyroid function tests with EDTA infusions in infancy and childhood. J. Pediatr. 88: 250 (1976).

231. Wara, D. W. and Ammann. A. J.: Thymosin treatment of children with primary immunodeficiency disease. Transplant. Proc. 10.203 (1978).

232. Weinberg. A. G. Mize, C. E., and Worthen, H. G.: The occurrence of hepatoma in the chronic form of hereditary tyrosinemia. J. Pediatr., 88 : $434(1976)$.

233. Whaun. J. M, and Oski. F. A.: Relation of red blood cell glutathione peroxidase to neonatal jaundice. J. Pediatr., 76: 555 (1970).

234. Whitley, R. J. Nahmias, A. J. Visintine, A. M. Flemming, C. L., Alford, C. A., and the Collaborative Antiviral Study Group of the National Institute of Allergy and Infectious Disease: The natural history of herpes simplex virus infection of mother and newborn. Pediatrics, 66: 489 (1980).

235. Williams, P. R. Fiser, R. H J J. Sperling, M. A. and Oh, W.: Effects of oral alanine feeding on blood glucose, plasma glucagon and insulin concentrations in small-for-gestational age infants. N. Engl. J. Med., 292:612 (1975).

236. Williamson, A. P., Montgomery, J. R.. South, M. A., and Wilson, R.: A special report: four-year study of a boy with combined immune deficiency maintained in strict reverse isolation from birth. Pediatr. Res., 11: 63 (1977).

237. Wilmore, D. W. and Dudrick, S. J.: Growth and development of an infant receiving all nutrients exclusively by vein. J. Am. Med. Assoc., 203: 860 (1968).
238. World Health Organization. Report on Social and Biological Effects on Perinatal Mortality. Vol. 1 (World Health Organization. New York, 1978).

239. Yakovac, W. C., Baker, L., and Hummeler, K.: Beta cell nesidioblastosis in idiopathic hypoglycemia of infancy. J. Pediatr., 79: 226 (1971)

240. Yang, S. Y., Levine, L. S., Zachmann, M., New, M. I., Prader, A., Oberfield, S. E., O'Neill, G. J., Pollack, M. S., and Dupont, B.: Mapping of the 21 hydroxylase deficiency gene within the HLA linkage group. Transplant Proc. 10: 753 (1978).

241. Yeager, A. S., Grumet, F. C., Hafleigh, E. B., Arvin, A. M., Bradley, J. S. and Prober, C. G.: Prevention of transfusion-acquired cytomegalovirus infections in newborn infants. J. Pediatr., 98: 281 (1981).

242. Yoshioka T and Roux, J. F.: In vitro metabolism of palmitic acid in human fetal tissue. Pediatr. Res., 6: 675 (1972).

243. Zarin-Ackerman, J., Lewis, M., and Driscoll, J. M., Jr.: Language development in 2-year-old normal and risk infants. Pediatrics, 59 (suppl.): 982 (1977).

244. We wish to acknowledge the administrative assistance of Dr. Eric Elliot, of the General Clinical Research Centers Branch, the Division of Research Resources, National Institutes of Health and the editorial assistance of Ms. Annette Terzian.

245. Reprint requests to ERS, Department of Pediatrics, UCLA Medical Center. Los Angeles, CA 90024

246. Received for publication March 1, 1983.

247. Accepted for publication May 11, 1983

\title{
The Effect of Small but Sustained Elevations in Circulating Growth Hormone on Fuel Metabolism in Growth Hormone Deficiency
}

\author{
WILLIAM V. TAMBORLANE. ${ }^{(13)}$ MYRON GENEL, STEPHANIE GIANFREDI. AND \\ JOSEPH M. GERTNER \\ Section of Pediatric Endocrinology, Department of Pediatrics, Yale University School of Medicine, \\ New Haven, Connecticul. USA
}

\section{Summary}

Although growth hormone $(\mathrm{GH})$ concentrations are not always pathologically elevated in patients with acromegaly, it has been suggested that the metabolic and somatic consequences of this condition may be due to a loss of the normal episodic secretion of GH. To examine the effects of maintaining modest but constant levels of circulating GH, we administered continuous subcutaneous infusions of growth hormone (CSIGH) to eight previously untreated GH-deficient children (6-19 yr).

CSIGH given for $90 \mathrm{~h}$ in doses equivalent to the standard dose for replacement therapy, raised mean serum GH levels from less than 3.0 to $5.9 \pm 1.0 \mathrm{ng} / \mathrm{ml}$. In comparison, 24-h mean GH levels in five normal adolescents averaged $10.1 \pm 1.5 \mathrm{ng} / \mathrm{ml}$. As expected, however, normals showed much more variability in GH concentration. The constant elevations in serum GH levels achieved with CSIGH produced significant impairment of oral glucose tolerance. During CSIGH, plasma glucose concentrations $60-120 \mathrm{~min}$ after oral glucose loading were $30-40 \mathrm{mg} / \mathrm{dl}$ higher than corresponding pre-infusion values $(P<0.01)$. This impairment of oral glucose tolerance during CSIGH occurred despite a doubling of the area under the insulin/time curve after oral glucose $(P<0.02$ versus pre-infusion area). Indeed, plasma insulin levels after oral glucose in patients on CSIGH exceeded those observed in normal controls, suggesting that CSIGH had induced a degree of insulin resistance.

There was a transient increase in plasma free fatty acid levels on the first day of CSIGH. Somatomedin-C concentration remained unchanged in four of six patients. We conclude that small but sustained increases in growth hormone concentrations in GH deficiency can, when infused continuously, have effects on fuel metabolism similar to those observed during pathologic GH hypersecretion.

\section{Abbreviations}

CSIGH, continuous subcutaneous infusions of growth hormone FFA, free fatty acids

GH, growth hormone

GH-secreting pituitary adenomas are characterized clinically by excessive somatic growth and hyperinsulinemia with or without glucose intolerance. In a recent study of patients with such adenomas, however. Clemmons et al. (3) demonstrated that the manifestations of acromegaly were not closely dependent on serum GH levels. Indeed, in certain individuals increased heel pad thickness and hyperglycemia were observed despite basal GH levels that lay within the normal range. 
In healthy man, the secretion of $\mathrm{GH}$ is episodic with secretory bursts occurring mainly during sleep. Between bursts, serum $\mathrm{GH}$ often falls to undetectable levels (4). It is thus possible that some of the metabolic consequences of acromegaly might be attributable to the loss of the normal pulsatile pattern of $\mathrm{GH}$ release even in the absence of marked elevations in serum GH concentrations.

To test this hypothesis we examined the metabolic effects of sustained GH infusions. Previously untreated GH-deficient children were studied to eliminate the variability that could be introduced by endogenous $\mathrm{GH}$ secretion. The infusions produced sharp changes in glucose tolerance and an apparent resistance to insulin even though measured GH levels never exceeded $14 \mathrm{ng} /$ $\mathrm{ml}$. These data support the view that metabolic derangements typical of those seen in acromegaly can be induced by sustained $\mathrm{GH}$ infusion even in the absence of marked elevations in serum GH concentrations.

\section{PATIENTS AND METHODS}

Eight children and adolescents with GH deficiency and 12 normal controls participated in the study after written informed consent had been obtained. GH-deficient patients had presented with growth failure and, on evaluation of pituitary function, had subnormal $\mathrm{GH}$ responses to provocative stimuli including insulin hypoglycemia. Clinical details including primary diagnosis and concurrent medical therapy are given in Table 1 . None of the patients had been treated with $\mathrm{GH}$ before the start of the present study, and none received regular glucocorticoid replacement. Patients 1 and 7 had been treated with glucocorticoids during acute stress but had not received any such therapy for at least 3 mo before study. The study protocol was as follows:

Patients were admitted to the Yale Children's Clinical Research Center on the day before study. At $0830 \mathrm{~h}$ on the following morning (after a $12-15$ h overnight fast) a catheter was inserted into an antecubital vein for blood sampling. The patients rested in a recumbent position for $30 \mathrm{~min}$ before blood samples were obtained for determinations of FFA, somatomedin-C, and GH. Oral glucose $(1.75 \mathrm{~g} / \mathrm{kg}$ body weight to a maximum of $100 \mathrm{~g})$ was then given and blood obtained every $30 \mathrm{~min}$ for $2 \mathrm{~h}$ for measurement of plasma glucose and insulin. The catheter was removed after completion of the oral glucose tolerance test.

On the evening of the same day $(1700 \mathrm{~h})$ a CSIGH was started using a small battery-powered infusion pump (Model AS-2C, Auto-Syringe, Inc.. Hooksett, NH). The pump was set to deliver $0.11 \mathrm{mi} / \mathrm{h}$ (given as $15 \mu \mathrm{L}$ pulses every $8 \mathrm{~min}$ ) and the concen-

Table 1. Clinical details of study subjects

\begin{tabular}{|c|c|c|c|c|c|}
\hline Patient & $\begin{array}{l}\text { Age } \\
(\mathrm{yr})\end{array}$ & Sex & Diagnosis & $\begin{array}{l}\text { Peak } \\
\text { GH* on }^{*} \text { testing } \\
(\mathrm{ng} / \mathrm{ml})\end{array}$ & $\begin{array}{l}\text { Concurrent } \\
\text { medications }\end{array}$ \\
\hline 1 & 15.1 & $\mathrm{~F}$ & $\begin{array}{l}\text { S/P pituitary ad- } \\
\text { enomectomy }\end{array}$ & 1 & $\begin{array}{l}\text { DDAVP } 10 \mu \mathrm{g} / \mathrm{d} \\
\text { Thyroxine } 150 \\
\mu \mathrm{g} / \mathrm{d}\end{array}$ \\
\hline 2 & 15.5 & $M$ & IGHD* & 1 & None \\
\hline 3 & 9.8 & $M$ & IGHD & 1 & None \\
\hline 4 & 6.1 & M & IGHD & 3 & None \\
\hline 5 & 8.5 & $M$ & IGHD & 2 & None \\
\hline 6 & 19.6 & $\mathrm{~F}$ & IGHD & 2 & None \\
\hline 7 & 14.7 & $\mathrm{~F}$ & $\begin{array}{l}\text { Post traumatic } \\
\text { panhypopitui- } \\
\text { tarism }\end{array}$ & 1 & $\begin{array}{l}\text { Thyroxine } 100 \\
\mu \mathrm{g} / \text { day }\end{array}$ \\
\hline 8 & 10.4 & M & $\begin{array}{l}\text { S/P medulloblas- } \\
\text { toma/GH* de- } \\
\text { ficiency }\end{array}$ & 2 & None \\
\hline
\end{tabular}

*IGHD. idiopathic growth hormone deficiency and GH. growth hormone.

$\dagger$ Insulin-induced hypoglycemia. tration of $\mathrm{GH}$ was adjusted so that the hourly infusion rate was equal to $2.1 \mu \mathrm{U} \cdot \mathrm{kg}^{-1} \cdot \mathrm{h}^{-1}$ corresponding to $0.05 \mathrm{U} \cdot \mathrm{kg}^{-1} \cdot 24 \mathrm{~h}^{-1}$. This dose was calculated to raise $\mathrm{GH}$ concentrations to values within the normal range and is comparable to the standard dose used in our clinic for conventional replacement therapy, $0.1 \mathrm{U}$. $\mathrm{kg}^{-1} \cdot$ dose $^{-1}$ three times weekly. $\mathrm{GH}$ was infused into the subcutaneous tissue of the anterior abdominal wall via a 27-gauge scalp vein needle, which was secured with tape. The injection site was inspected and changed daily. Apart from this brief interruption, the infusion was continued for a total of $90 \mathrm{~h}$. Patients were fully ambulatory during the $\mathrm{GH}$ infusions and consumed a diet which, by detailed history, approximated their usual home intake.

Each morning during the infusion blood was taken in the fasting state for measurement of FFA and GH levels. In addition, $\mathrm{GH}$ levels were measured daily in the late afternoon (between 1600 and $1800 \mathrm{~h}$ ) during Gh administration. On the morning of the fourth infusion day a second oral glucose tolerance test was carried out and fasting blood samples obtained just as on the first (pre-infusion) morning. GH infusion was discontinued after the completion of this second glucose tolerance test. Results of the oral glucose tolerance tests were compared with those of studies conducted in seven non-obese children and adolescents (ages, 7-13 yr) who had volunteered to act as normal controls. Five additional normal control children (ages, 11-15 yr) were admitted to the Children's Clinical Research Center for 24-h monitoring of $\mathrm{GH}$ levels. These subjects were studied under ambulatory conditions and blood was obtained every $2 \mathrm{~h}$ via an indwelling catheter for measurement of GH levels.

Glucose was measured on a YSI Analyzer (Yellow Springs Instrument Company, Yellow Springs, $\mathrm{OH}$ ) using a glucose oxidase technique. Insulin and $\mathrm{GH}(9)$, and somatomedin-C (Nichols Institute, San Pedro, CA) were measured by radioimmunoassay. The coefficient of variation of the plasma insulin assay is $8-10 \%$. Plasma aminoacids were measured with an automated aminoacid analyzer (Beckman Instruments, Inc., Fullerton, CA) after deproteination with sulfosalycilic acid. FFA were measured by the method of Novak et al. (7). Group data are presented as mean \pm SEM. Student's paired $t$ test was used for the statistical analysis of the data.

\section{RESULTS}

CSIGH produced small but sustained elevations in $\mathrm{GH}$ concentrations (Fig. 1). Mean plasma GH levels (less than $3 \mathrm{ng} / \mathrm{ml}$, pre-treatment) increased to $5.9 \pm 1.0 \mathrm{ng} / \mathrm{ml}$ during the infusion. Even more importantly, in individual patients the coefficient of variation of fasting and random afternoon serum GH concentrations averaged only $21.3 \pm 2.3 \%$ during the infusion. Normal controls, on the other hand, showed slightly greater mean $\mathrm{GH}$ concentrations during $24-\mathrm{h}$ monitoring $(10.1 \pm 1.5 \mathrm{ng} / \mathrm{ml})$, as well as much greater serum $\mathrm{GH}$ fluctuations. The coefficient of variation in individual normal subjects averaged $105 \pm 8 \%(P<$ 0.001 versus values in deficient patients during $\mathrm{CSIGH}$ ).

As shown in Figure 2, $90 \mathrm{~h}$ of CSIGH had no significant effect on fasting plasma glucose or insulin but sharply altered oral glucose tolerance. Plasma glucose values were $30-40 \mathrm{mg} / \mathrm{dl}$ above pre-infusion values from $60-120 \mathrm{~min}$ after oral glucose $(P<$ $0.01)$. Impaired glucose tolerance produced by $\mathrm{GH}$ infusion occurred in spite of an increase in circulating insulin concentrations. Plasma insulin levels during CSIGH were significantly elevated as compared with pre-treatment values beyond $60 \mathrm{~min}$ $(P<0.05)$, and the area under the insulin/time curve was almost doubled $\left(10.2 \pm 4.3\right.$ versus $\left.5.7 \pm 1.6 \mathrm{mU} \cdot \mathrm{ml}^{-1} \cdot \mathrm{min}^{-1}, P<0.02\right)$. Figure 3 compares plasma glucose and insulin levels $120 \mathrm{~min}$ after glucose loading in the study patients before and after $\mathrm{CSIGH}$ with corresponding values for normal controls. Before treatment, plasma glucose and insulin levels in deficient patients were similar to corresponding values in the normal subjects but they rose to values significantly higher than normal after $90 \mathrm{~h}$ of $\mathrm{GH}$ infusion. 

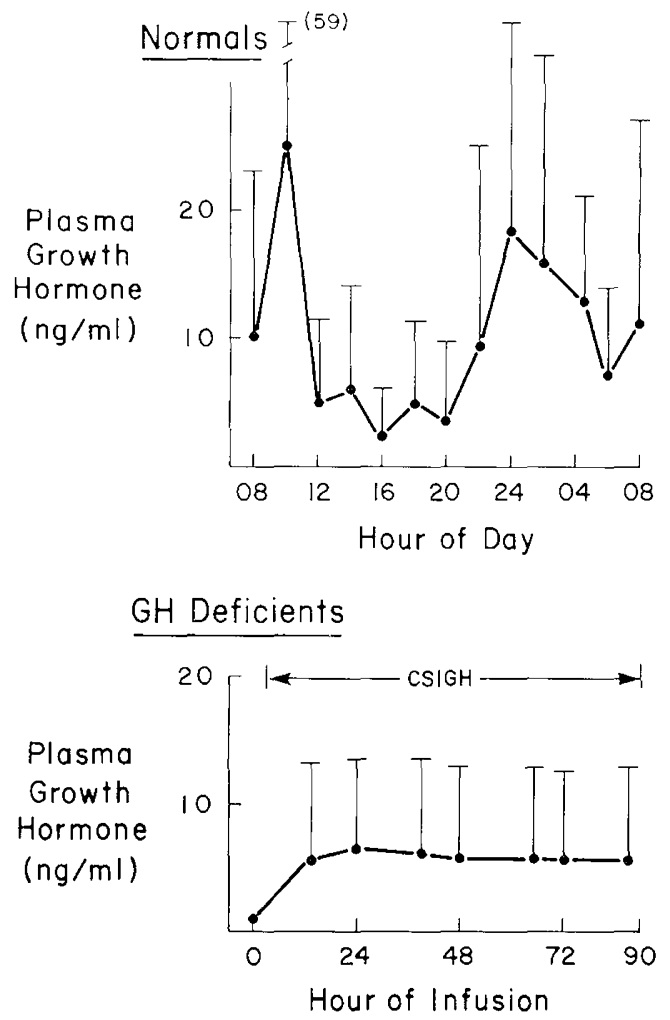

Fig. 1. This figure contrasts the stable plateau levels of growth hormone achieved during a serial sampling over $4 \mathrm{~d}$ of continuous subcutaneous infusions of growth hormone $(\mathrm{CSIGH})$ in deficient patients with the fluctuations in growth hormone concentrations during $24 \mathrm{~h}$ monitoring in normal controls.

CSIGH induced only transient changes in fasting FFA concentrations. FFA levels rose on the first morning of therapy (from $521 \pm 81$ to $930 \pm 123 \mu \mathrm{M}, P<0.05$ ) but on subsequent mornings fasting FFA values returned to pre-treatment levels. No significant changes were observed in the fasting concentrations of alanine or branched-chain aminoacids. Paired measurements of somatomedin- $C$ concentration were obtained in six of the patients before and at completion of the GH infusion. Each patient had somatomedin-C levels in the hypopituitary range before treatment, including three subjects with values below the detection limits of the essay (Fig. 4). After CSIGH, somatomedin$C$ levels increased sharply in two, while remaining virtually unchanged in the other subjects (Fig. 4).

Some erythema was observed at the injection site in most patients during infusion. This almost invariably cleared within $24 \mathrm{~h}$ of changing the needle site and was never the cause of more than minor discomfort. There were no signs of fat atrophy or sclerosis on examination of the skin at intervals up to $1 \mathrm{yr}$ after the study.

\section{DISCUSSION}

Responsiveness to a variety of hormones appears to depend on the timing and frequency of hormonal signals as well as to the absolute values of concentration. For example, the somatic effects of hypercortisolism are observed in Cushing's disease when the normal diurnal fluctuation in serum cortisol is lost, even in the absence of gross elevations in cortisol levels. In the case of gondotropin releasing hormone, $\mathrm{GnRH}$, it has been shown that exogenous hormone given intermittently (to mimic the natural secretion of the hormone) can stimulate the target cells whereas these are suppressed when exposed to constant levels of gonadotropin releasing hormone (2).

As far as GH is concerned, it is generally accepted that chronic marked elevations in concentration increase the risk of diabetes mellitus and cause hyperinsulinemia in patients with normal fasting glucose levels. A similar impairment of glucose disposal was reported after administration of large, pharmacologic, doses of $\mathrm{GH}$ to normal subjects (6). But the somatic and metabolic consequences of acromegaly were also observed while GH concentrations were relatively low (3); thus, the manifestations of acromegaly may be due, at least in part, to a loss of the natural periodicity of $\mathrm{GH}$ release. This issue is, as yet, unresolved. Previous studies examining the metabolic effects of "physiologic" doses of $\mathrm{GH}$ in man have generally raised serum $\mathrm{GH}$ to levels observed during stress $(\sim 20-40 \mathrm{ng} / \mathrm{ml})$, that is, to values higher than those seen in the basal state $(1,7)$.

In the present study, we administered standard replacement doses of $\mathrm{GH}$ to previously untreated $\mathrm{GH}$-deficient patients by continuous subcutaneous infusion for $90 \mathrm{~h}$. The infusion caused modest but sustained increases in circulating $\mathrm{GH}$ concentrations (Fig. 1). Despite the small increases in GH levels, the infusions caused marked alterations in fuel metabolism. Oral glucose tolerance was impaired and FFA levels increased transiently.

\section{ORAL GLUCOSE TOLERANCE BEFORE AND DURING CSIGH}

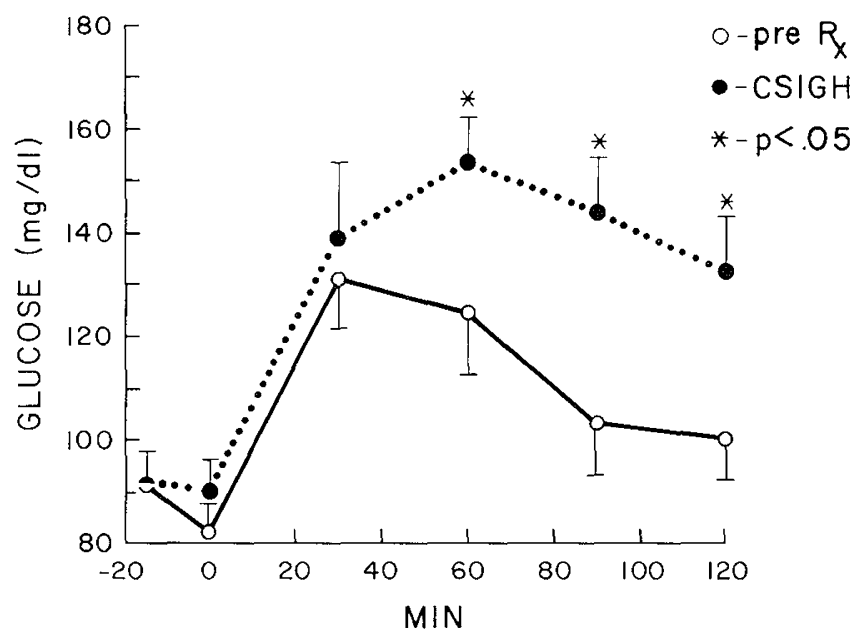

\section{PLASMA INSULIN AFTER ORAL GLUCOSE; BEFORE AND DURING CSIGH}

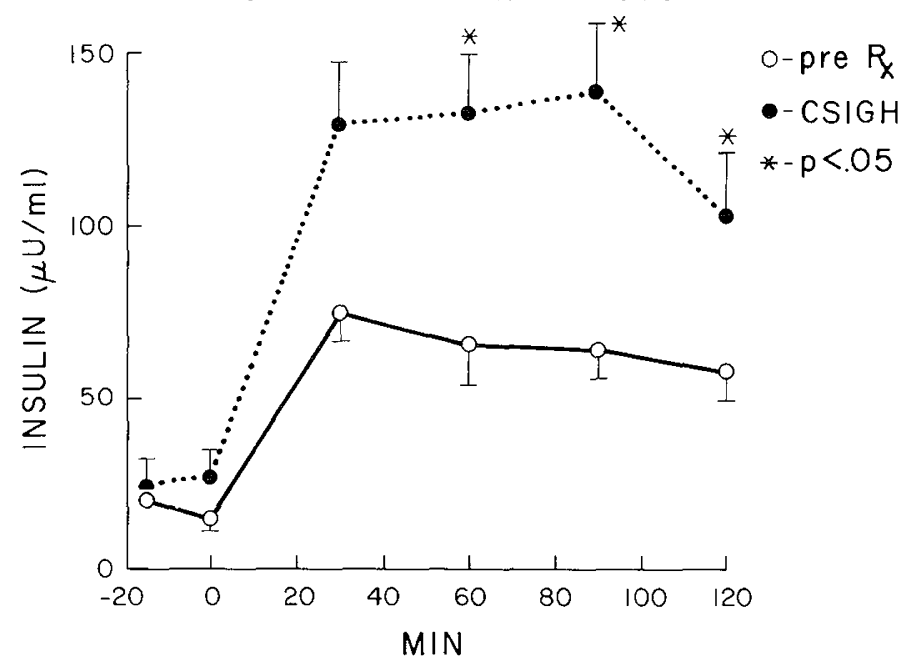

Fig. 2. Mean plasma glucose and immunoreactive insulin levels from oral glucose tolerance tests performed before and during continuous subcutaneous growth hormone (CSIGH) infusion. Asterisks indicate levels significantly $(P<0.05)$ greater than the pretreatment valucs. 


\section{ORAL GLUCOSE TOLERANCE \\ PLASMA GLUCOSE AND INSULIN AT I2O MINUTES}

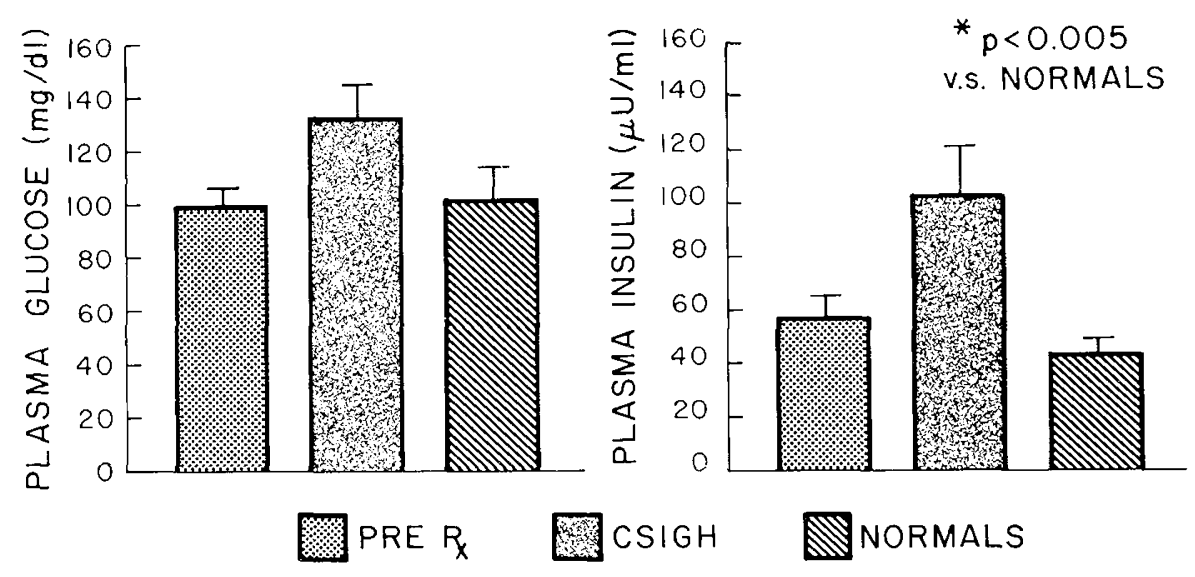

Fig. 3. Plasma glucose and insulin levels $120 \mathrm{~min}$ after a standard oral glucose load in study subjects before and during continuous subcutaneous glucose infusion of growth hormone (CSIGH) and in seven normal adolescent controls. Note that during growth hormone infusion both glucose and insulin were greater than in the controls.

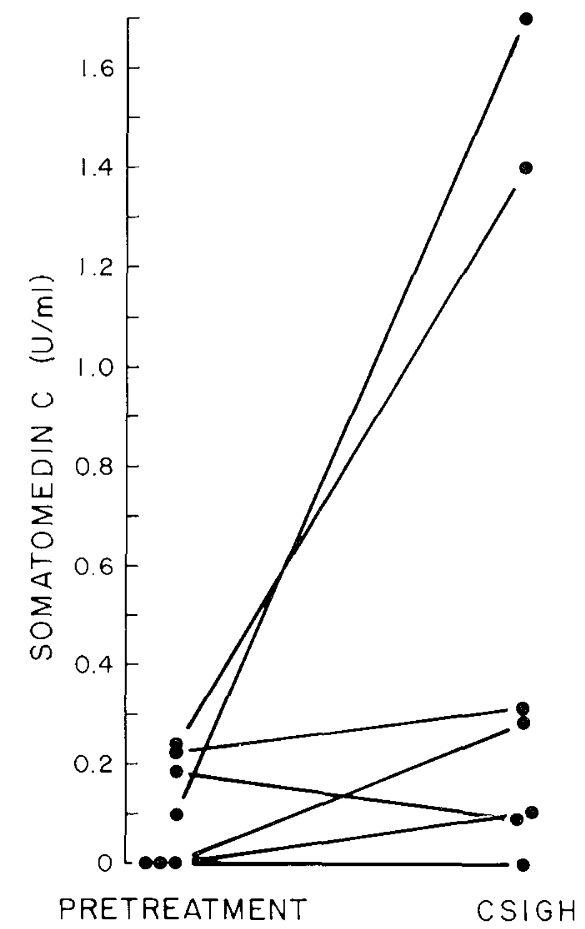

Fig. 4. Somatomedin-C levels in seven of the patients, measured before and after $90 \mathrm{~h}$ of continuous subcutaneous growth hormone infusion $(\mathrm{CSIGH})$.

Glucose tolerance was impaired despite an exaggerated insulin response to oral glucose. It remains to be determined whether this insulin resistance, developing during GH infusion, is mediated at the level of the insulin receptor or elsewhere. The report of Rizza et al. (8) however, suggests that prolonged $(12 \mathrm{~h})$ elevations of $\mathrm{GH}$ in normal adults induces insulin resistance on the basis of a postreceptor defect.

It is particularly noteworthy that the 2-h glucose and insulin values increased during CSIGH to values greater than those seen in non-GH deficient children and adolescents. These metabolic changes were observed even though serum GH levels during infusion were comparable to (or even less than) average values in normal children and adolescents. In contrast to the normal large fluctuations, however, GH concentrations during infusion varied little for each individual patient. The observed metabolic effects of infusion might thus have been due to its sustained nature. The changes in glucose and insulin do not appear to be secondary to the effects of the infusion on somatomedin- $\mathrm{C}$ because only a minority of patients showed a rise in somatomedin-C concentration.

\section{REFERENCES AND NOTES}

1. Adamson, V. and Cerasi, E.: Acute effects of exogenous growth hormone in man: time- and dose-bound modification of glucose tolerance and glucoseinduced insulin release. Acta Endocrinol., 80: 247 (1975).

2. Belchet7. P. E. Plant, T. E. Nakai, U., Keogh, E. J.. and Knobil E. Hypophysial response to continuous and intermittent delivery of hypothalamic gonadotropin-releasing hormone. Science. 202: 631 (1978)

3. Clemmons. D.R., Van Wyk. J. J.. Ridgway. E. C.. Kliman. B., Kjellberg. R. $\mathcal{V}$.. and Underwood, L. E.: Evaluation of acromegaly by radioimmunoassay of somatomedin-C. N. Engl. J. Med. 301:1138(1979).

4. Finkelstein, J. W. Roffwarg. H. P., Roger. R. M.. kreem, J., and Hellman, L.: Age-related change in the twenty-four hour spontaneous secretion of growth hormone. J. Clin. Endoc. Metab.. 35: 665 (1972).

5. Hollobaugh. S. L.. Tzagournis. M.. Fold, R. L.. et al: The diabetogenic action of human growth hormone: glucose fatty acid interrelationships. Mctabolism. 17: $485(1968)$

6. MacGorman. L.R.. Rissa. R. A.. and Gerich, J. E.: Physiological concentrations of growth hormonc exert insulin-like and insulin antagonistic effects on both hepatic and extrahepatic tissues in man. J. Clin. Endocrinol. Metab., 53: 556 (1981).

7. Novak. J.: Colorimetric ultramicromethod for the determination of free fatty acids. J. Lipid.Res.. 6: 431 (1965).

8. Rizza. R. A.. Mandarino. L. J.. and Gerich. J. E.: Effects of growth hormone on insulin action in man: mechanism of insulin resistance. impaired suppression of glucose production, and impaired stimulation of glucose utilization. Diabetes. 31:663 (1982).

9. Rosselin. G.. Assan. R.. Yalow, R.S., and Berson. S. A.: Separation of antibody bound and unbound peptide hormones labelled with ${ }^{131}$ I by talcum powder and precipitated silica. Nature. 212:355 (1966)

10. Presented in part at the 1981 meeting of the Society for Pediatric Research. San Francisco. Catifornia.

11. We wish to thank Drs. Robert Sherwin and Rosa Hendler for their advice and collaboration throughout this project. We are grateful to the nurses of the Yale Children's Clinical Research Center. for the technical assistance of Tatiana Sergeievsky, Mary Waleski and Ralph Jacobs, and to Helen Black who typed the manuscript. Human growth hormone was a gift of the National Hormone and Pituitary Agency (Director Dr. S. Raiti). AS-2C Syringe Pumps were kindy donated by Auto-Syringe. Inc.. Hookset1. New Hampshire.

12. Supported by Grant RR-00125 to the Yale Children`s Clinical Research Center and the CLINFO Computer Resource. William V. Tamborlane, M. D., is the recipient of NIH Clinical Investigator Award AM00621.

13. Requests for reprints should be addressed to: Dr. William V. Tamborlanc Yale University School of Medicine. P. O.Box 3333. LMP 3103. New Haven. Cr 06510.

14. Received for publication May 27. 1983

15. Accepted for publication September 9. 1983. 